\title{
Structure activity relationship of tautomers of curcumin: a review
}

\author{
Sameera A. Rege, Megha Arya, Shamim A. Momin \\ Institute of Chemical Technology, Mumbai, India.
}

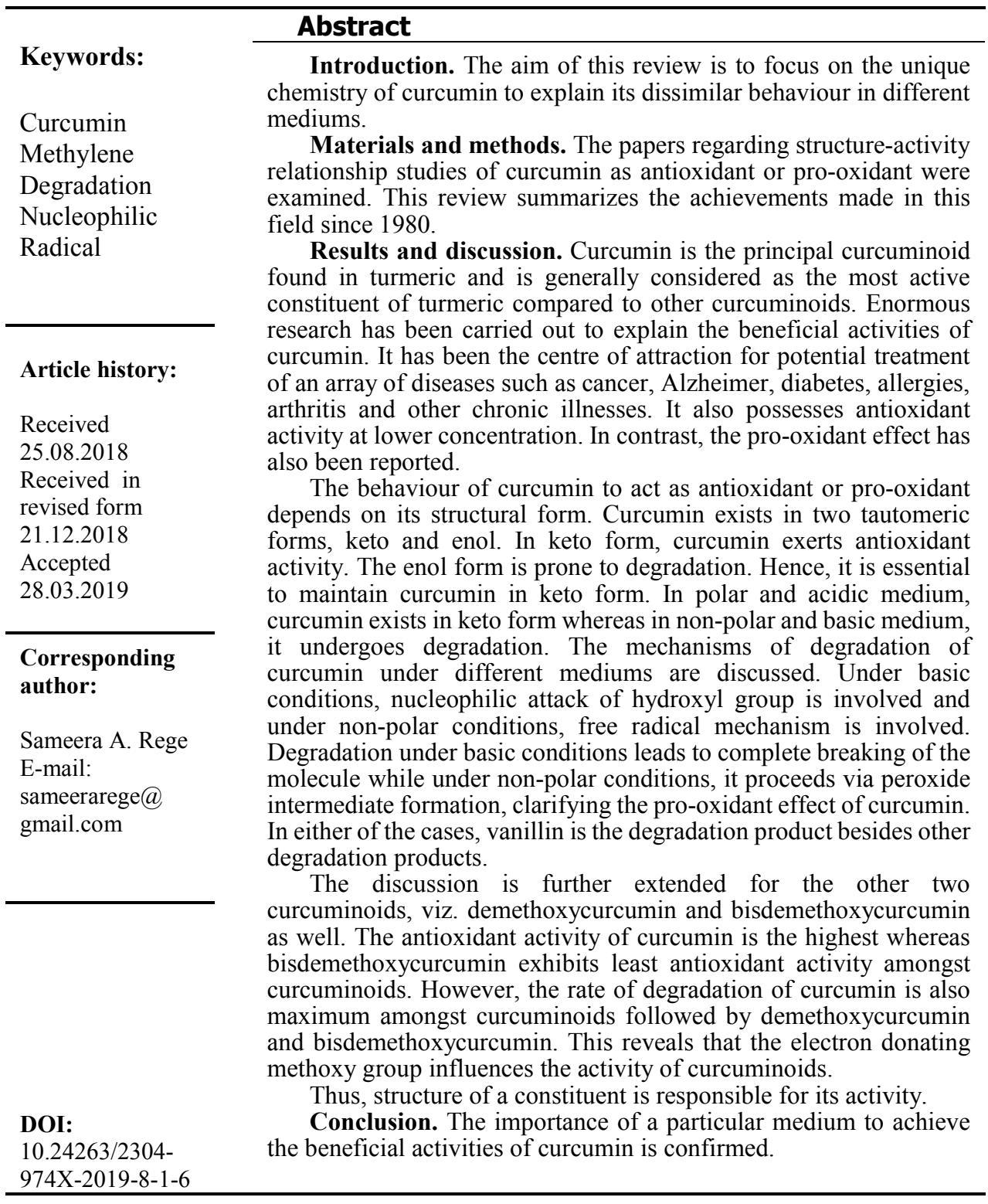




\section{Introduction}

Curcuminoids are the major polyphenolic compounds found in turmeric rhizome. The curcuminoids include curcumin (the main bioactive component), demethoxycurcumin and bisdemethoxycurcumin $[1,2,3]$. The unique structure of curcumin, which has the phenolic hydroxyl groups, heptadiene chain and diketone moiety $[4,5,6]$, is responsible for all the therapeutic activities of curcumin such as anti-inflammatory, antitumor, anticancer, antiHIV, antibacterial, antidiabetic [7, 8, 9, 10, 11, 12, 13]. It is used as an antioxidant [9], a wound healing agent $[14,15,16]$ and to prevent Alzheimer disease [17, 18]. Recently, it has also been reported as an antidepressant agent [19]. However, the pro-oxidant effect of curcumin is also observed [20]. This review emphasizes the fundamental of the stabilization and degradation of curcumin with the help of existing theories [21, 22], explaining its dissimilar behaviour.

\section{Materials and methods}

Review is constructed on the basis of previously available research articles.

\section{Result and discussion}

\section{Structure of keto and enol tautomers}

The keto enol tautomerism in curcumin is because of the presence of carbonyl groups on the carbon number 3 and 5 in heptadiene ring [23, 24, 25, 26] (Figure 1). The stabilization of enol tautomer with respect to the keto tautomer is due to the conjugation of the carbonyl double bond with the enol double bond and a pi orbital system, i.e., phenyl group in conjugation with the conjugated $\mathrm{C}=\mathrm{C}$ double bonds [27]. The enol tautomer is characterized by the formation of strong intramolecular hydrogen bonding compared to intermolecular hydrogen bonding which exists in the keto form [28]. The enolisation of curcumin brings about a fundamental change, i.e., the polar keto tautomer is converted to the non-polar enol tautomer. The dependency of the structure of curcumin on solvent has already been proved as it exhibits different $\lambda_{\max }$ in different solvents $[29,30]$. Depending upon the polarity of the medium, curcumin exists in different proportion as a tautomeric mixture of keto and enol forms in the medium. Both the tautomers get solubilized in the medium through different forces. Polar-polar solubilization takes place by means of dipole-dipole forces, while nonpolar-non-polar and polar-non-polar solubilization takes place by means of dispersion forces. Like prefers like. Hence, in the polar medium, the activity of keto form predominates while in the non-polar medium, the activity of enol form predominates [31].

\section{Role of methylene group in curcumin}

In the keto form of curcumin (1-i), the heptadienone linkage between the two methoxyphenol rings contains an active methylene group. Jovanovic et al. [32] proved that curcumin acts as an antioxidant only in the keto form by donating $\mathrm{H}$-atom from the methylene group, i.e., $-\mathrm{CH}_{2}$ group which is between two electron withdrawing carbonyl groups. The resulting carbon radical formed after abstraction of $\mathrm{H}$-atom (3) is stabilized by resonance (4 and 5) (Figure 2). The active methylene group takes up the reaction site only in acidic or polar medium. 


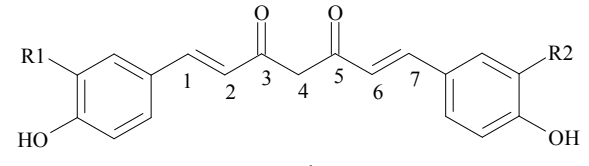

1

Keto form

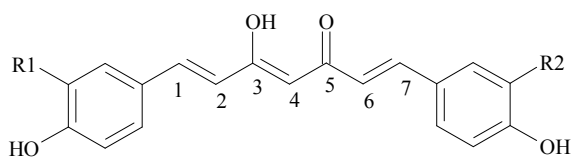

2

Enol form

where,

Figure 1. Tautomerism of curcuminoids

(i) $\mathrm{R} 1=\mathrm{R} 2=-\mathrm{OCH}_{3}$; Curcumin (Diferuloylmethane)

(ii) $\mathrm{R} 1=-\mathrm{OCH}_{3}, \mathrm{R} 2=-\mathrm{H}$; Demethoxycurcumin ( $p$-Hydroxycinnamoyl feruloylmethane)

(iii) $\mathrm{R} 1=\mathrm{R} 2=-\mathrm{H}$; Bisdemethoxycurcumin ( $p, p^{\prime}$-Dihydroxydicinnamoylmethane)

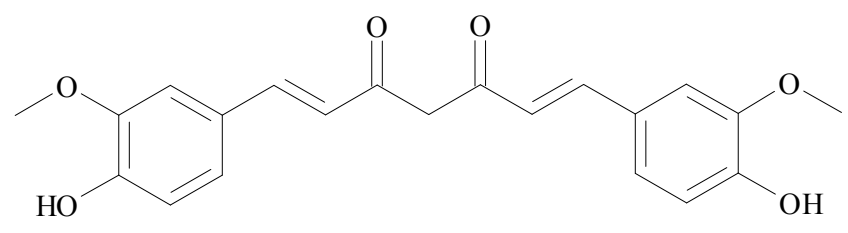

1-i
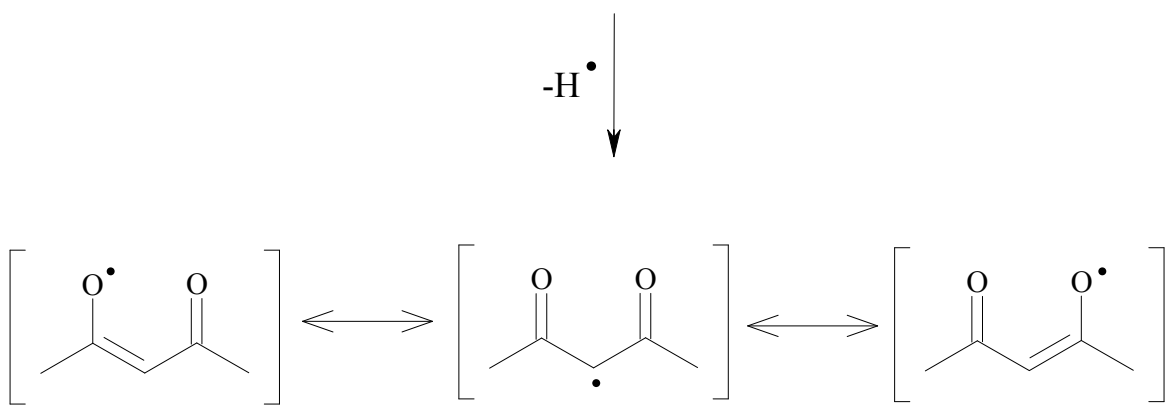

4

3

5

Figure 2. Donation of H-atom from active methylene group

In basic or non-polar medium, the phenolic moiety of curcumin primarily gets involved in the reaction and $-\mathrm{CH}_{2}$ group involves in enolic form (2-i) [33]. Curcumin is prone to degradation in alkaline [34] and non-polar medium [31].

\section{Degradation of curcumin}

Various studies have been carried out to study the degradation of curcumin. Depending upon the medium, whether it is alkaline or non-polar, degradation of curcumin takes place through different pathways. 
In basic medium, the degradation occurs by nucleophilic attack of basic -OH (hydroxyl) ion. Feruloylmethane (6) and ferulic acid (7) are formed by the alkaline hydrolysis of curcumin. The feruloylmethane further undergoes hydrolysis to form vanillin (8) and acetone (9) [35] (Figure 3). Thus, the degradation pathway under basic medium involves breaking of heptadienone moiety, leading to disappearance of active methylene group that mainly imparts antioxidant activity to curcumin. Hence, curcumin cannot act as an antioxidant.

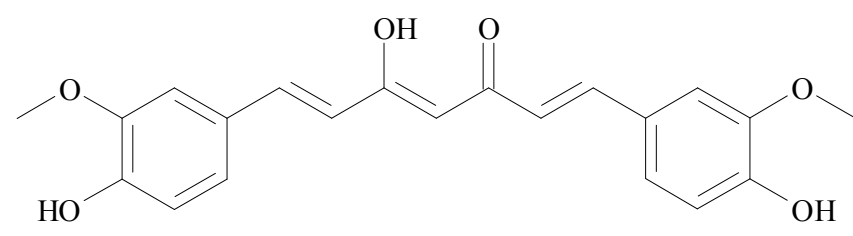

2-i

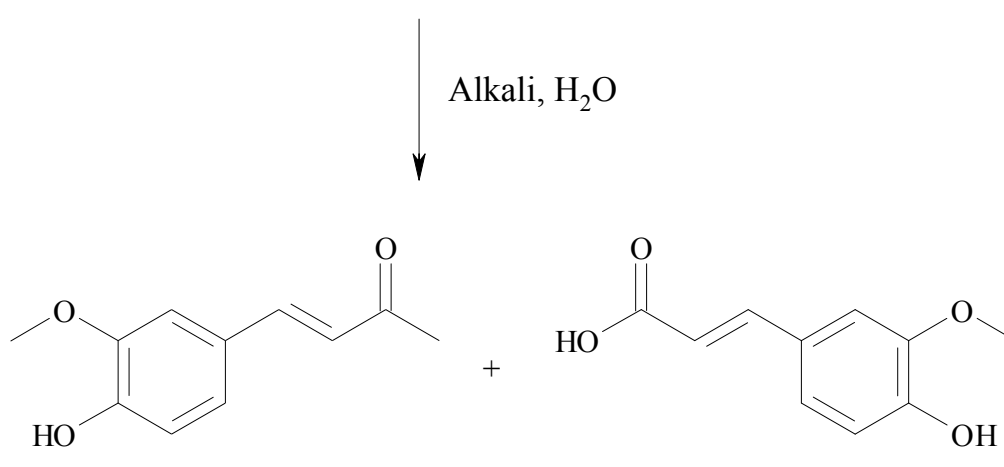

6

(i) Formation of primary products

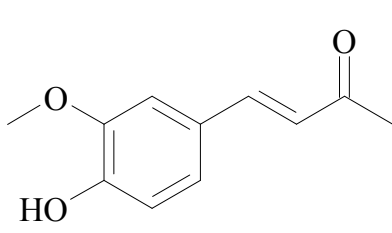

6

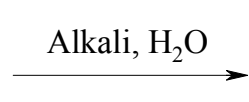

(ii) Formation of secondary products

Figure 3. Degradation of curcumin under alkaline medium

In non-polar medium, Masuda et al. [36] postulated the degradation of curcumin through radical formation to form vanillin and ferulic acid [37, 38, 39]. The enol form of curcumin degrades to form oxy radical I (10) initially, which further gets converted to carbon radical I (11) and carbon radical II (12). Because of conjugation, carbon radical II is more stable than carbon radical I. Both the radicals independently react with molecular oxygen to produce two types of peroxy radicals $(13,16)$, which get cyclized at adjacent positions. The 
cyclic intermediates $(14,17)$ get decomposed to form stable products through an abstraction of the hydrogen atom from hydrogen atom donor compounds. The enol form of trans-6-(4'hydroxy-3'-methoxyphenyl)-2,4-dioxo-5-hexenal (15-i) and vanillin are formed by the carbon radical I [40] whereas ferulic acid is formed by the carbon radical II. The enol form of trans-6-(4'-hydroxy-3'-methoxyphenyl)-2,4-dioxo-5-hexenal can tautomerize to keto form (15-ii) (Figure 4). Thus, the degradation pathway under non-polar medium involves autoxidation of curcumin. Hence, curcumin acts as a pro-oxidant.

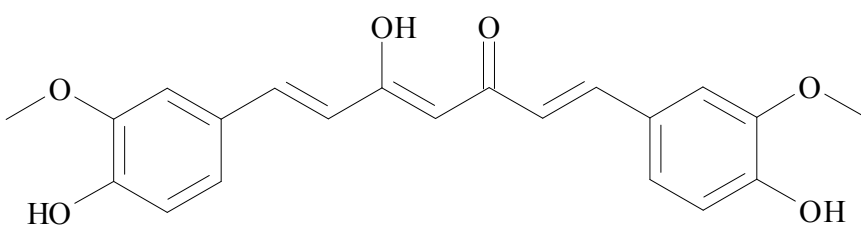

2-i
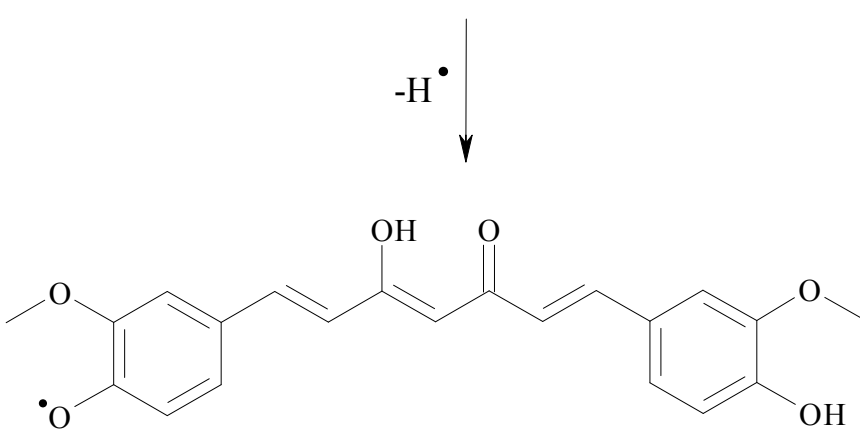

10

Oxy radical I (Highly unstable)

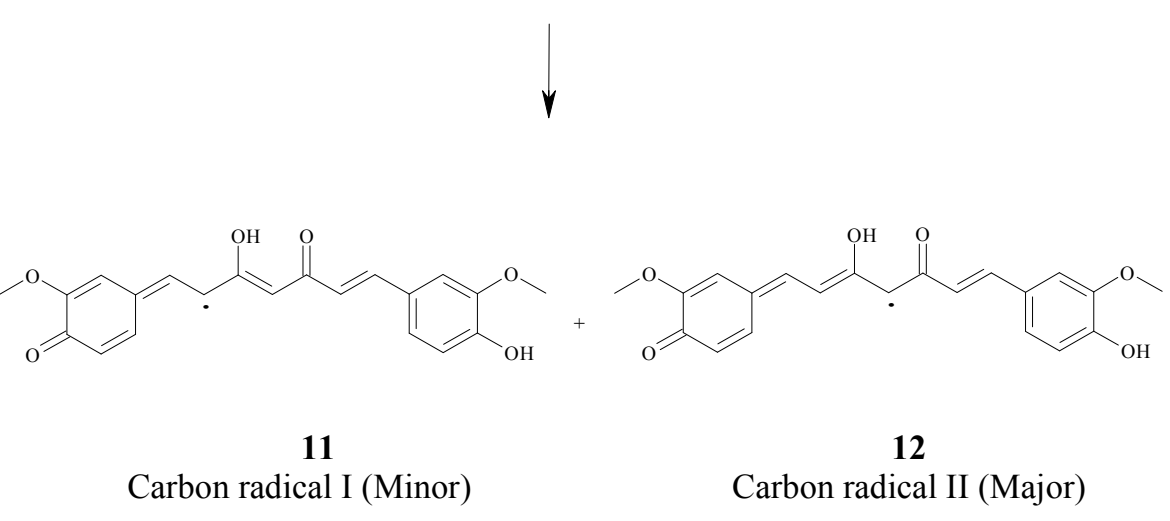

(i) Radicals generated by curcumin 

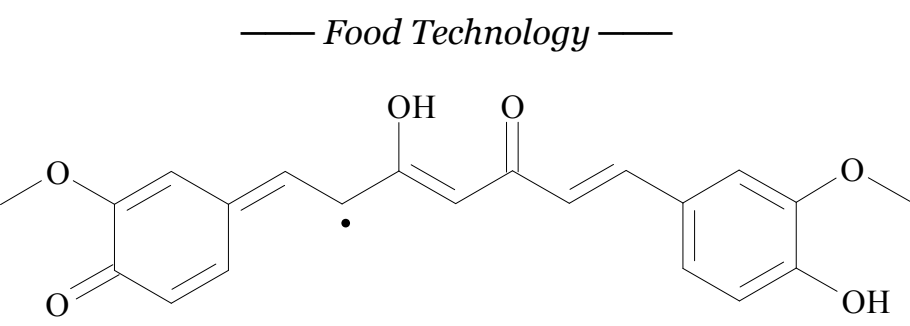

11
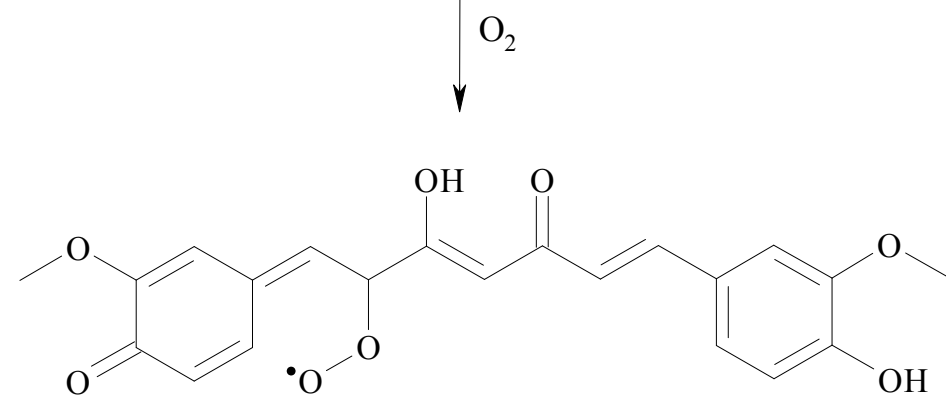

13

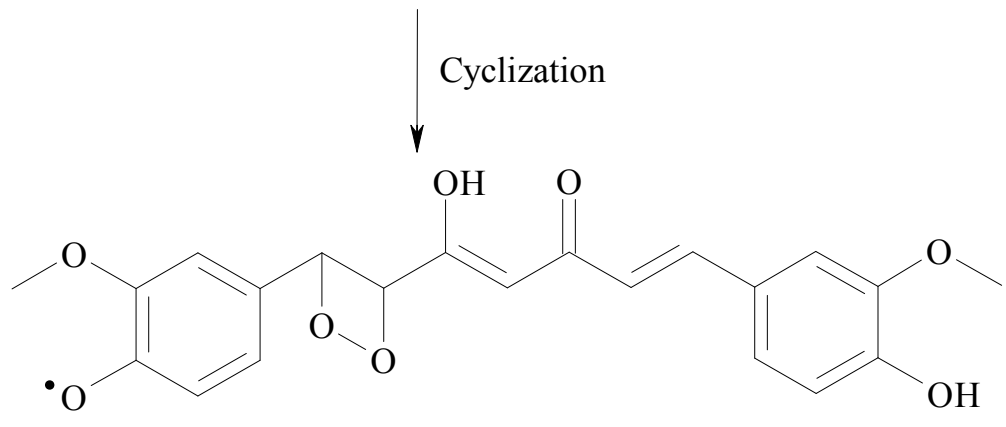

14

$$
+\mathrm{H}^{\bullet}
$$<smiles>COc1cc(/C=C/C(=O)/C=C(\O)C(=O)C=O)ccc1O</smiles> 


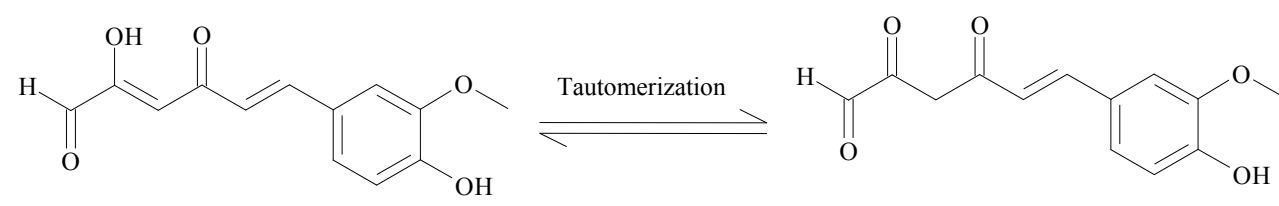

15-i

enol form 15-ii

keto form

(ii) Reaction of radical I with $\mathrm{O}_{2}$

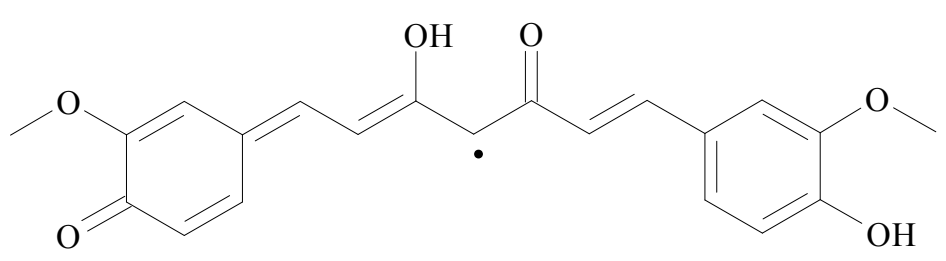

12

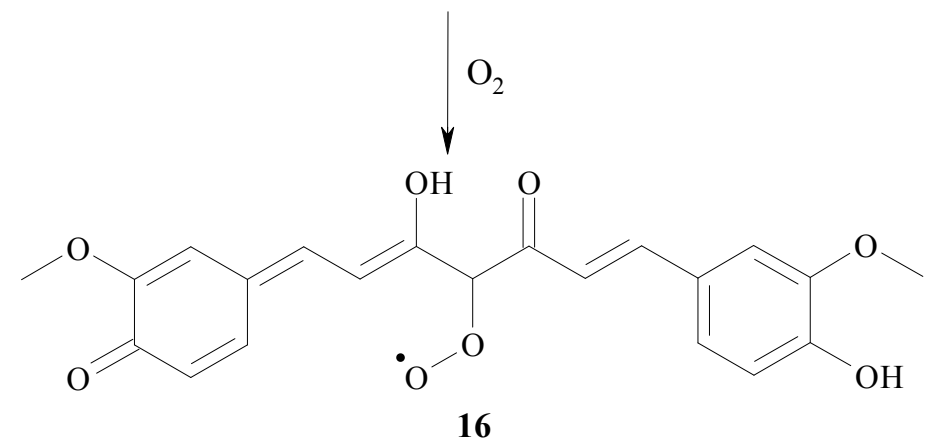

Cyclization

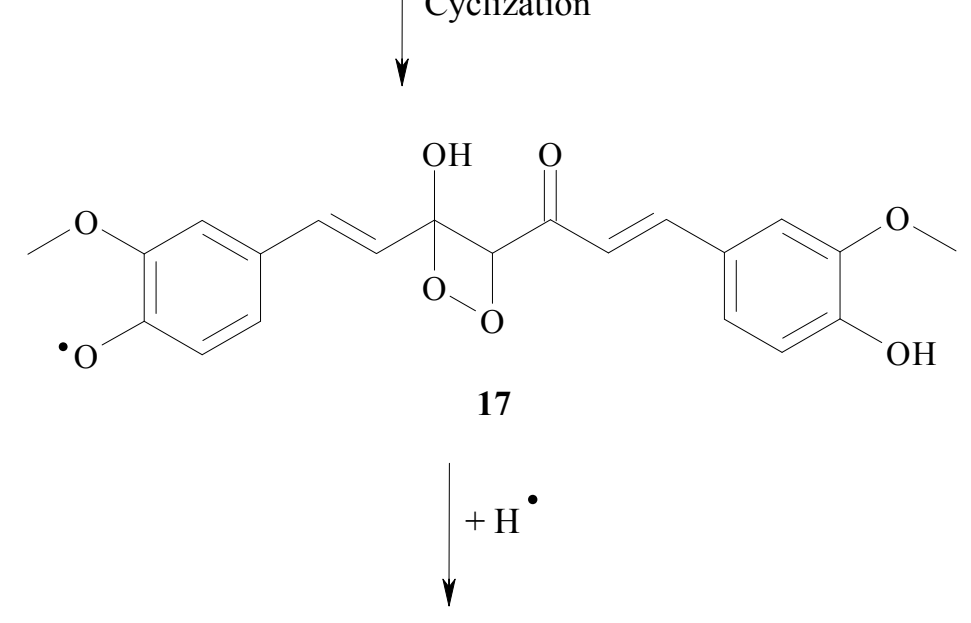

—Ukrainian Food Journal. 2019. Volume 8. Issue $1-$ 


\title{
— Food Technology
}<smiles>COc1cc(/C=C/C(=O)O)ccc1O</smiles>

7<smiles>COc1cc(/C=C/C(=O)C=O)ccc1O</smiles>

18

(iii) Reaction of radical II with $\mathrm{O}_{2}$

Figure 4. Degradation of curcumin under non-polar medium

\section{Degradation of trans-6-(4'-hydroxy-3'-methoxyphenyl)-2,4-dioxo-5-hexenal}

It can be envisaged [40] from the studies that similar to curcumin, the enol tautomer of trans-6-(4'-hydroxy-3'-methoxyphenyl)-2,4-dioxo-5-hexenal (15-i) may undergo degradation under alkaline medium to form feruloylmethane (Figure 5), which gets converted to vanillin and acetone on hydrolysis as mentioned previously.

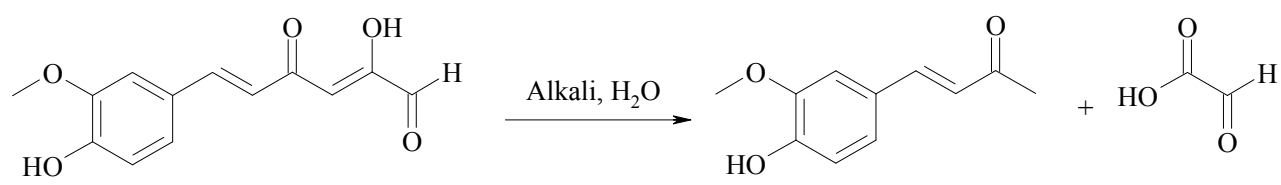

\author{
$\begin{array}{lll}15-i & 6 & 19\end{array}$ \\ Figure 5. Degradation of \\ Trans-6-(4'-hydroxy-3'-methoxyphenyl)-2,4-dioxo-5-hexenal \\ under alkaline medium
}

In non-polar medium, the enol tautomer of trans-6-(4'-hydroxy-3'-methoxyphenyl)2,4-dioxo-5-hexenal undergoes degradation to form oxy radical II (20), which gets converted to carbon radical III (21) and carbon radical IV (22). Like carbon radical II, carbon radical IV is more stable than carbon radical III because of conjugation. The radicals so formed combine with molecular oxygen forming two types of peroxy radicals $(23,26)$, which get cyclized at adjacent positions $(24,27)$. As discussed previously, the stable products from these cyclic intermediates are obtained by simultaneous abstraction of the hydrogen atom from hydrogen atom donor compound and decomposition (Figure 6). Carbon radical III forms vanillin while carbon radical IV forms ferulic acid. 


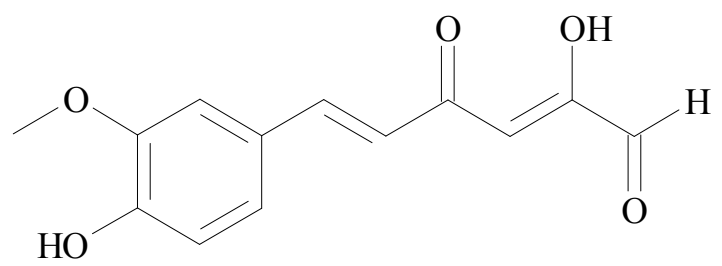

15-i

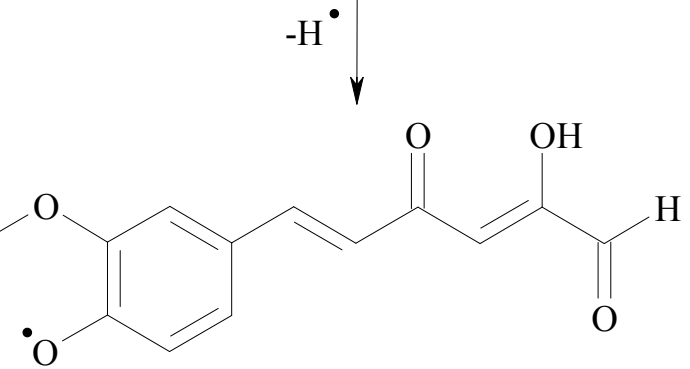

20

Oxy radical II (highly unstable)<smiles>COC1=C/C(=C/C(=O)/C=C(\O)C(=O)/C=C/C(=O)/C=C(\O)CC(=O)C=O)C=CC1=O</smiles>

21

Carbon radical III (Minor)
22

Carbon radical IV (Major)

(i) Radicals generated by Trans-6-(4'-hydroxy-3'-methoxyphenyl)-2,4-dioxo-5-hexenal

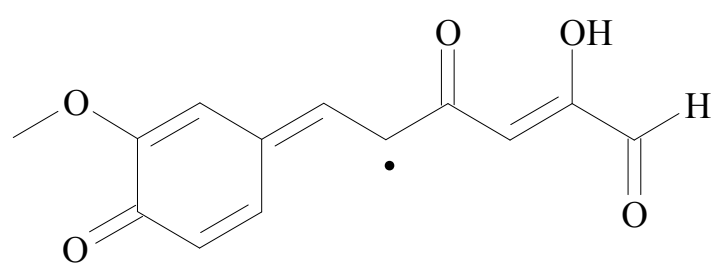

21 


$$
\mathrm{O}_{2}
$$$$
\text { r }
$$

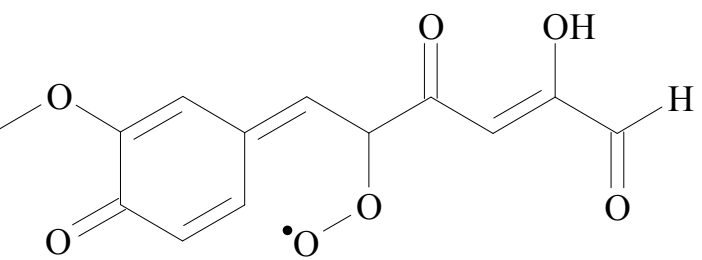

23

Cyclization

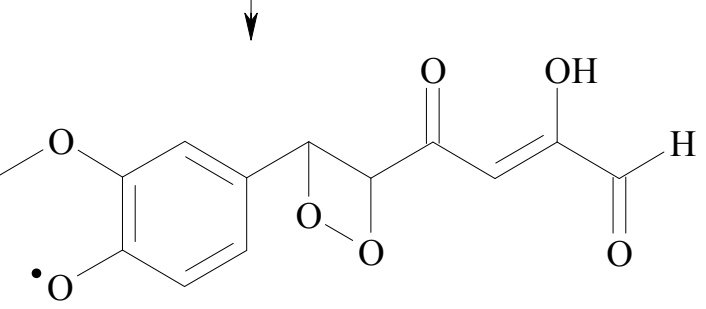

24

$$
+\mathrm{H}^{\bullet}
$$

r<smiles>COc1cc(C=O)ccc1O</smiles>

(ii) Reaction of radical III with $\mathrm{O}_{2}$

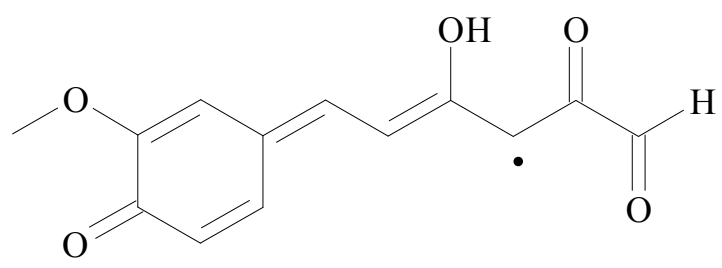

22 


$$
\mathrm{O}_{2}
$$

$$
\text { r }
$$<smiles>COC1=C/C(=C/C=C(\O)C(O[O])C(=O)C=O)C=CC1=O</smiles>

26

Cyclization<smiles>COc1cc(/C=C/C2(O)OOC2C(=O)C=O)ccc1[O-]</smiles>

27

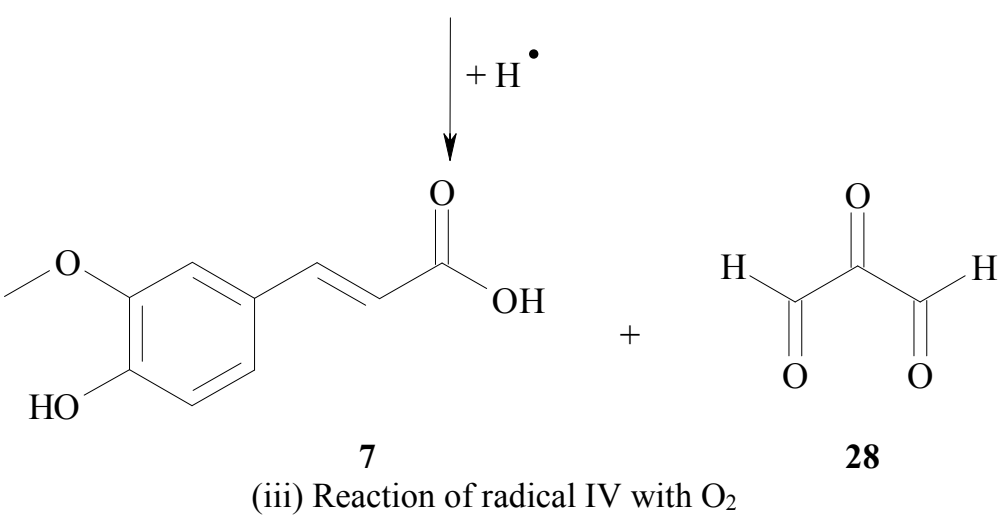

Figure 6. Degradation of Trans-6-(4'-hydroxy-3'-methoxyphenyl)-2,4-dioxo-5-hexenal under non-polar medium

\section{Inference about degradation products}

The aforementioned mechanisms indicated that vanillin is the degradation product of curcumin in alkaline as well as non-polar medium along with other products in the respective mediums. Consequently, these mechanisms support the formation of more amount of vanillin during the degradation of curcumin.

The overall discussion is represented in Figure 7. 


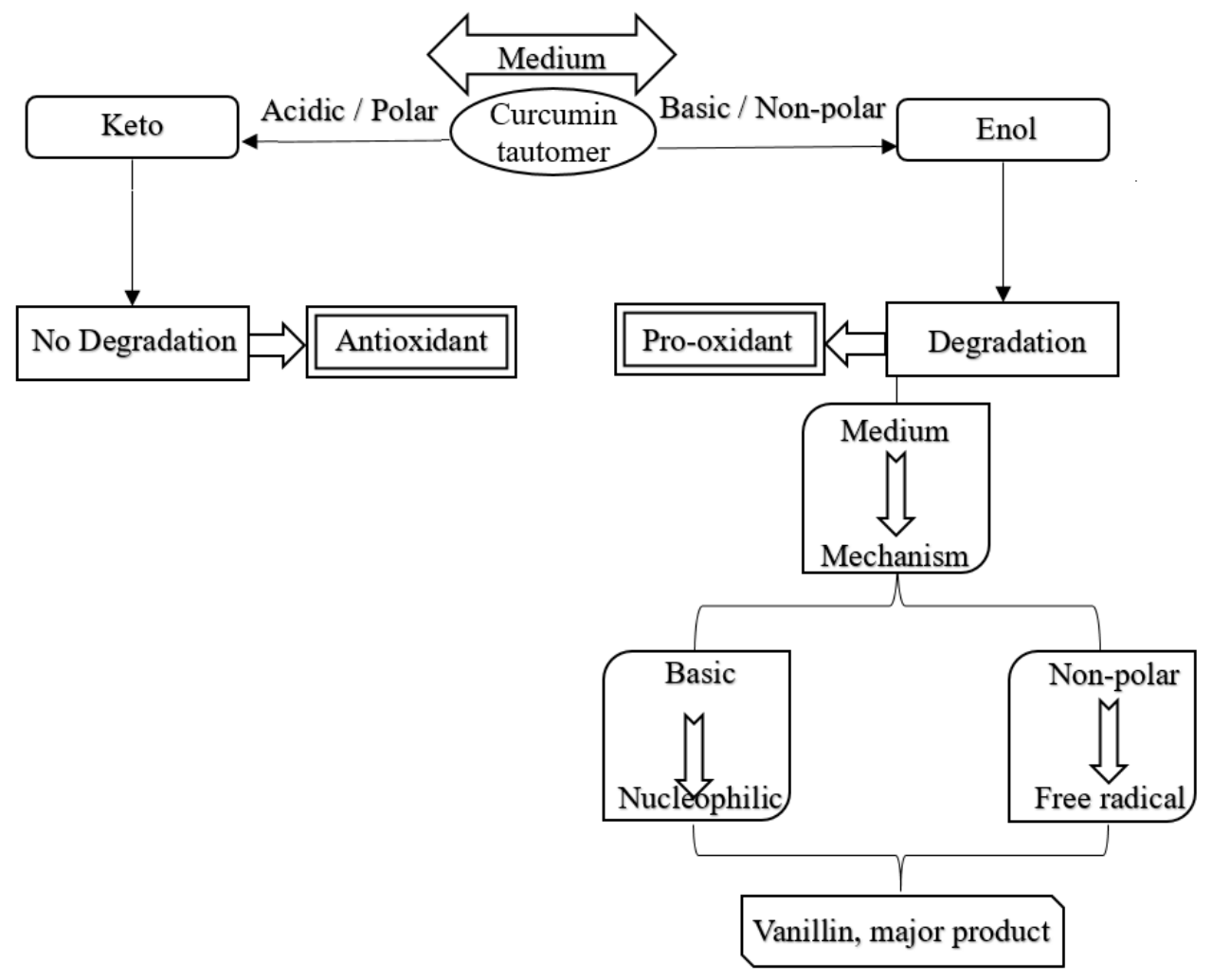

Figure 7. The activity of tautomers of curcumin in different mediums

\section{Structure activity relationship of demethoxycurcumin and bisdemethoxy- curcumin and comparison with curcumin}

General introduction about demethoxycurcumin and bisdemethoxycurcumin. Similar to curcumin, the other two curcuminoids (i.e., demethoxycurcumin and bisdemethoxycurcumin) contain phenolic hydroxyl groups, heptadiene chain and diketone moiety (Figure 1), which account for the various therapeutic activities of demethoxycurcumin and bisdemethoxycurcumin such as antioxidant, anti-inflammatory, anticancer [41, 42, 43]. Both are useful for the prevention of Alzheimer disease [44]. Since phenolic groups and heptadienone moiety are responsible for the general chemistry of curcumin as notified earlier, the theories postulated for curcumin hold good for other two curcuminoids.

Comparison of antioxidant activity of curcumin with demethoxycurcumin and bisdemethoxycurcumin. Although all the three curcuminoids exhibit identical activities, their reactivity differs. Jayaprakasha et al. [41] evaluated that the antioxidant potential of curcumin is the highest followed by demethoxycurcumin and bisdemethoxycurcumin. This finding is valid only when curcuminoids do not undergo degradation, by employing acidic or 
polar medium. On the contrary, under basic or non-polar medium, bisdemethoxycurcumin is less susceptible to degradation than demethoxycurcumin, which is still less susceptible to degradation than curcumin [45]. Besides $\mathrm{pH}$ or nature of the medium, the structure of the phenolic compounds has an impact on the stability of the phenolic compounds [46]. The methoxy group plays an important role in determining the activity of curcuminoids.

Nevertheless, in curcuminoids the antioxidant activity is mainly due to the active methylene group; the presence of electron donating methoxy group at ortho to phenolic hydroxyl group also contributes to the antioxidant activity of the molecule, by increasing the electron density on the hydroxyl group by means of an inductive effect [47]. Amongst three curcuminoids, the existence of two methoxy groups in curcumin ensures the maximum antioxidant activity. By the virtue of the occurrence of one methoxy group in demethoxycurcumin, it has better antioxidant activity than bisdemethoxycurcumin, which is devoid of methoxy group [48].

The electron donating group favours enol tautomer [49]. Hence, owing to two methoxy groups, the equilibrium shifting towards formation of enol tautomer is maximum in case of curcumin and minimum in case of bisdemethoxycurcumin among three curcuminoids. Correspondingly, bisdemethoxycurcumin is less prone to degradation than demethoxycurcumin, which in turn is less prone to degradation than curcumin.

Accordingly, in acidic or polar solvent, the rate of antioxidant activity of curcuminoids and in basic or non-polar solvent, the rate of degradation of curcuminoids is same, i.e., curcumin $>$ demethoxycurcumin $>$ bisdemethoxycurcumin.

\section{Conclusion}

Curcumin is a specially gifted molecule provided by Mother-Nature to protect humans from chronic health problems. By looking at its chemical structure, we can presume that its chemistry is also very simple. However, with increasing scientific research, curcumin appears to be a more complex, unique and difficult structure to comprehend. It is a symmetrical molecule found abundance in turmeric with relatively high stability in its natural form. In view of the degradation study of curcumin, this review attempts to justify the formation of different degradation products under various reaction mediums. The heptadienone moiety in curcuminoids needs to be protected from degradation to avail its beneficial effects. Since the mechanisms are elucidated on the basis of reported literature, further studies need to be carried out regarding degradation of curcuminoids, which will account for the formation of unknown degradation products.

\section{References}

1. Jayaprakasha G.K., Jena B.S., Negi P.S., Sakariah K.K. (2002), Evaluation of antioxidant activities and antimutagenicity of turmeric oil: A byproduct from curcumin production, Zeitschrift für Naturforschung C, 57(9-10), pp. 828-835.

2. Ravindranath V., Satyanarayana M.N. (1980), An unsymmetrical diarylheptanoid from Curcuma longa, Phytochemistry, 19(9), pp. 2031-2032.

3. Limtrakul P., Anuchapreeda S., Buddhasukh, D. (2004), Modulation of human multidrugresistance MDR-1 gene by natural curcuminoids, BioMed Central Cancer, 4(13), pp. 1-6.

4. Ruby A.J., Kuttan G., Babu K.D., Rajasekharan K.N., Kuttan R. (1995), Anti-tumor and antioxidant activity of natural curcuminoids, Cancer Letters, 94(1), pp. 79-83. 
5. Kunchandy E., Rao M.N.A. (1990), Oxygen radical scavenging activity of curcumin, International Journal of Pharmaceutics, 58(3), pp. 237-240.

6. Sokmen M., Khan M.A. (2016), The antioxidant activity of some curcuminoids and chalcones, Inflammopharmacology, 24(2-3), pp. 81-86.

7. Niranjan A., Prakash D. (2008), Chemical constituents and biological activities of turmeric (Curcuma longa L.) - A review, Journal of Food Science and Technology, 45(2), pp. 109 116.

8. Jain S.K., Rains J., Jones, K. (2006), Effect of curcumin on protein glycosylation, lipid peroxidation, and oxygen radical generation in human red blood cells exposed to high glucose levels, Free Radical Biology and Medicine, 41(1), pp. 92-96.

9. Stano J., Grancai D., Neubert K., Kresanek, J. (2000), Curcumin as a potent antioxidant, Ceská a Slovenská Farmacie, 49(4), pp. 168-170.

10. Cole G.M., Teter B., Frautschy S.A. (2007), Neuroprotective effects of curcumin, Advances in Experimental Medicine and Biology, 595, pp. 197-212.

11. Thangapazham R.L., Sharma A., Maheshwari R.K. (2007), Beneficial role of curcumin in skin diseases, Advances in Experimental Medicine and Biology, 595, pp. 343-357.

12. Sun X., Liu Y., Li C., Wang X., Zhu R., Liu C., Liu H., Wang L., Ma R., Fu M., Zhang D., Li Y. (2017), Recent advances of curcumin in the prevention and treatment of renal fibrosis, BioMed Research International, 2017, pp. 1-9.

13. Qin S., Huang L., Gong J., Shen S., Huang J., Ren H., Hu H. (2017), Efficacy and safety of turmeric and curcumin in lowering blood lipid levels in patients with cardiovascular risk factors: a meta-analysis of randomized controlled trials, Nutrition Journal, 16(68), pp. 110.

14. Kant V., Gopal A., Pathak N.N., Kumar P., Tandan S.K., Kumar D. (2014), Antioxidant and anti-inflammatory potential of curcumin accelerated the cutaneous wound healing in streptozotocin-induced diabetic rats, International Immunopharmacology, 20(2), pp. 322330 .

15. Govindarajan V.S. (1990), Turmeric - Chemistry, technology, and quality, Critical Reviews in Food Science and Nutrition, 12(3), pp. 199-301.

16. Ammon H.P., Wahl M.A. (1991), Pharmacology of Curcuma longa, Planta Medica, 57(1), pp. 1-7.

17. Ono K., Hasegawa K., Naiki H., Yamada M. (2004), Curcumin has potent antiamyloidogenic effects for Alzheimer's beta-amyloid fibrils in vitro, Journal of Neuroscience Research, 75(6), pp. 742-750.

18. Ruidas B., Chaudhury S.S. (2017), Role of curcumin in treatment of Alzheimer disease, International Journal of Neurorehabilitation, 4(3), pp. 1-7.

19. Panahi Y., Badeli R., Karami G.R., Sahebkar A. (2015), Investigation of the efficacy of adjunctive therapy with bioavailability-boosted curcuminoids in major depressive disorder, Phytotherapy Research, 29(1), pp. 17-21.

20. Semwal A.D., Sharma G.K., Arya S.S. (1997), Antioxygenic activity of turmeric (Curcuma longa) in sunflower oil and ghee, Journal of Food Science and Technology, 34(1), pp. 6769.

21. Muhammad A., Shahab-Uddin A., Khan U., Hannan A., Mohiuddin E., Asif M. (2010), Curcuma longa and curcumin: A review article, Romanian Journal of Biology - Plant Biology, 55(2), pp. 65-70.

22. Suresh D., Gurudutt K.N., Srinivasan K. (2009), Degradation of bioactive spice compound: curcumin during domestic cooking, European Food Research and Technology, 228(5), pp. $807-812$.

23. (2004), Curcumin, Chemical and Technical Assessment, 61st JECFA. pp. 1-8. Available at: ftp://ftp.fao.org/es/esn/jecfa/cta/CTA_61_Curcumin.pdf. 
24. Kawano S., Inohana Y., Hashi Y., Lin J.M. (2013), Analysis of keto-enol tautomers of curcumin by liquid chromatography/mass spectrometry, Chinese Chemical Letters, 24(8), pp. 685-687.

25. Payton F., Sandusky P., Alworth W.L. (2007), NMR study of the solution structure of curcumin, Journal of Natural Products, 70(2), pp. 143-146.

26. Rege S.A., Momin S.A., Wadekar S.D., Bhowmick D.N., Pratap A.P. (2014), Effect of demethoxycurcumin and bisdemethoxycurcumin on antioxidant activity of curcumin in refined sunflower oil, Journal of Food Processing and Preservation, 38(1), pp. 296-303.

27. Kalsi P.S. (2006), Chapter 2: Delocalized Chemical Bonding, Organic Reactions and Their Mechanisms (Second Edition), New Delhi, India: New Age International (P) Limited, pp. 37-80.

28. Skyes, P. (2013), Chapter 10: Carbanions and Their Reactions, A Guidebook to Mechanism in Organic Chemistry (Sixth Edition), New Delhi, India: Pearson Education, Ltd., pp. 270 298.

29. Chignell C.F., Bilskj P., Reszka K.J., Motten A.G., Sik R.H., Dahl T.A. (1994), Spectral and photochemical properties of curcumin, Photochemistry and Photobiology, 59(3), pp. 295302 .

30. Khopde S.M., Priyadarsini K.I., Palit D.K., Mukherjee T. (2000), Effect of solvent on the excited-state photophysical properties of curcumin, Photochemistry and Photobiology, 72(5), pp. 625-631.

31. Rege S.A., Momin S.A., Bhowmick D.N., Pratap A.P. (2012), Stabilization of emulsion and butter like products containing essential fatty acids using kalonji seeds extract and curcuminoids, Journal of Oleo Science, 61(1), pp. 11-16.

32. Jovanovic S.V., Steenken S., Boone C.W., Simic M.G. (1999), H-atom transfer is a preferred antioxidant mechanism of curcumin, Journal of American Chemical Society, 121(41), pp. 9677-9681.

33. Jagannathan R., Abraham P.M., Poddar P. (2012), Temperature-dependent spectroscopic evidences of curcumin in aqueous medium: A mechanistic study of its solubility and stability, The Journal of Physical Chemistry B, 116(50), pp. 14533-14540.

34. Khurana A., Ho C.T. (1988), High performance liquid chromatographic analysis of curcuminoids and their photo-oxidative decomposition compounds in Curcuma longa L., Journal of Liquid Chromatography, 11(11), pp. 2295-2304.

35. Tonnesen H.H., Karlsen J. (1985), Studies of curcumin and curcuminoids: V. Alkaline degradation of curcumin, Zeitschrift für Lebensmittel-Untersuchung und-Forschung, 180(2), pp. 132-134.

36. Masuda T., Hidaka K., Shinohara A., Maekawa T., Takeda Y., Yamaguchi H. (1999), Chemical studies on antioxidant mechanism of curcuminoid: Analysis of radical reaction products from curcumin, Journal of Agricultural and Food Chemistry, 47(1), pp. 71-77.

37. Sandur S.K., Pandey M.K., Sung B., Ahn K.S., Murakami A., Sethi G., Limtrakul P., Badmaev V., Aggarwal B.B. (2007), Curcumin, demethoxycurcumin, tetrahydrocurcumin and turmerones differentially regulate anti-inflammatory and antiproliferative responses through a ROS-independent mechanism, Carcinogenesis, 28(8), pp. 1765-1773.

38. Zhu J., Sanidad K.Z., Sukamtoh E., Zhang G. (2017), Potential roles of chemical degradation in the biological activities of curcumin, Food \& Function, 8(3), pp. 907-914.

39. Schneider C., Gordon O.N., Edwards R.L., Luis P.B. (2015), Degradation of curcumin: From mechanism to biological implications, Journal of Agricultural and Food Chemistry, 63(35), pp. 7606-7614.

40. Wang Y.J., Pan M.H., Cheng A.L., Lin L.I., Ho Y.S., Hsieh C.Y., Lin J.K. (1997), Stability of curcumin in buffer solutions and characterization of its degradation products, Journal of Pharmaceutical and Biomedical Analysis, 15(12), pp. 1867-1876. 
41. Jayaprakasha G.K., Rao L.J., Sakariah K.K. (2006), Antioxidant activities of curcumin, demethoxycurcumin and bisdemethoxycurcumin, Food Chemistry, 98(4), pp. 720-724.

42. Ramsewak R.S., DeWitt D.L., Nair M.G. (2000), Cytotoxicity, antioxidant and antiinflammatory activities of curcumins I-III from Curcuma longa, Phytomedicine, 7(4), pp. 303-308.

43. Zhang L.J., Wu C.F., Meng X.L., Yuan D., Cai X.D., Wang Q.L., Yang J.Y. (2008), Comparison of inhibitory potency of three different curcuminoid pigments on nitric oxide and tumor necrosis factor production of rat primary microglia induced by lipopolysaccharide, Neuroscience Letters, 447(1), pp. 48-53.

44. Park S.Y., Kim D.S. (2002), Discovery of natural products from Curcuma longa that protect cells from beta-amyloid insult: a drug discovery effort against Alzheimer's disease, Journal of Natural Products, 65(9), pp. 1227-1231.

45. Price L.C., Buescher R.W. (1997), Kinetics of alkaline degradation of the food pigments curcumin and curcuminoids, Journal of Food Science, 62(2), pp. 267-269.

46. Friedman M., Jurgens H.S. (2000), Effect of $\mathrm{pH}$ on the stability of plant phenolic compounds, Journal of Agricultural and Food Chemistry, 48(6), pp. 2101-2110.

47. Khan M.A., Shahidi F. (2001), Effects of natural and synthetic antioxidants on the oxidative stability of borage and evening primose triacylglycerols, Food Chemistry, 75(4), pp. 431437.

48. Somparn P., Phisalaphong C., Nakornchai S., Unchern S., Morales N.P. (2007), Comparative antioxidant activities of curcumin and its demethoxy and hydrogenated derivatives, Biological and Pharmaceutical Bulletin, 30(1), pp. 74-78.

49. Antonov L., Deneva V., Simeonov S., Kurteva V., Crochet A., Fromm K.M., Shivachev B., Nikolova R., Savarese M., Adamo C. (2015), Controlled tautomeric switching in azonaphthols tuned by substituents on the phenyl ring, ChemPhysChem. 16(3), pp. 649-657. 